\title{
12
}

\section{CARE FOR THE UNCARED (FOR)}

\section{Slum Redevelopment and the Emerging Challenges of Accessing Care for the Urban Poor in Delhi}

\author{
Niroopa Subrahmanyam
}

\section{Introduction}

Housing, water, and sanitation are fundamental prerequisites for the care and well-being of the urban poor in metropolitan cities. In the capital city of India, these services along with health, education, and social security are extended via the Basic Services for the Urban Poor (BSUP) program only to a small percentage of the urban poor that live in 'planned colonies' and have access to regularized housing. ${ }^{1} \mathrm{~A}$ disproportionate number of the remaining population of urban poor, however, live in 'unplanned colonies'2 marked by sharp social divisions, no promise of a secure legal tenure, and a visible lack of basic services. The illegality of their tenure has led to both de jure and de facto exclusions of these households from accessing basic services for their survival. This means the only legitimate way for the urban poor to access basic services in the city is via access to regularized housing.

At present the urban poor can access regularized housing either through state subsidized social housing schemes or by buying property from the private housing market. The eligibility to state social housing schemes is highly complex and uncertain and is determined mainly through the level and nature of encroachment of the slum colonies on private or public land. In comparison, buying or renting property from the private housing market is uncomplicated.

However, according to the Report of the Technical Group on Urban Housing Shortage (Kundu 2012) the current private housing stock, although in abundance, is only affordable to a very small proportion of the urban population, most of whom either already live in 'acceptable dwelling units, want to shift from a rented accommodation to a self-owned house, or want to upgrade their living standards. The segment of the poor that live in 'unacceptable conditions' with limited access to basic services does not have the adequate financial means "to even enter the housing market to claim ownership or acquire rental housing" (ibid.: v). According to the presented data, $62 \%$ of the total surveyed households having a monthly household income of $₹ 10,000$ (US\$132) are at the risk of having no access to regularized housing nor effectively to basic services as well (Kundu 2012).

In 2009, the central government initiated its new affordable urban housing scheme, the Rajiv Awas Yojana (RAY), whose specific aim was first to address the challenge of providing 
tenurial security, and second, to tackle the lack of affordable housing options for the poor. The scheme looked at making the guidelines of provision of housing and basic services easier both for the state as well as the private developer. Unlike the previous state-initiated social housing schemes, RAY proposes two major policy shifts: The scheme extends the right to basic shelter and basic services to all existing slums regardless of their legal status and it offers support to private developers and encourages their participation through a Public-Private Partnership (PPP) model that subsidizes the cost of land and provides Floor Area Ratio (FAR) discounts to ensure the feasibility of subsidized housing. In principle, "RAY becomes the closest policy articulation to a Right to Shelter" and the first scheme to recognize the rights of the urban poor in accessing basic services irrespective of the legality of their existing housing (Bhan et al. 2014: 12).

While on paper RAY's objective is to ensure affordable housing and basic services for all, in reality the scheme has come under intense scrutiny for falling short of its promises. Firstly, despite claiming the contrary, on the ground, the feasibility of RAY hinges on setting strict criteria of eligibility in order for slum households to be entitled to a legal tenure and by that effect to basic services. The criteria for eligibility set by the state housing authority is vague and have not been defined within the policies of the scheme, leaving many slum households in conditions worse than they were prior to the redevelopment. In addition, the redevelopment proposed within RAY comes at the cost of hasty and unethical slum evictions and demolitions that have uprooted households from their communities and displaced them from their modes of occupation. There is a lack of effective policies to protect the rights of the slum dwellers and adequately compensate the displaced slum households. Lastly and most importantly, the policies within RAY give little regard to the importance of analyzing and mapping the basic services that already exist within the informal settings of the slum and represent "a level of investment and affordability that is more aligned to the incomes and aspirations of the urban poor" (ibid.: 16).

While RAY was seen as an ingenious opportunity for the state to lay the foundations for a policy framework for accessing both housing and basic services for the poor, on the ground, however, the implementation of the scheme has been inadequate. The confusion around the eligibility to the scheme has created an atmosphere of fear and mistrust between the state and the poor affecting their willingness to voluntarily participate in their own rehabilitation process. At the same time, the dismantling of their existing urban fabric to give way to modern high-rise towers has exposed the state's need for territorial accumulation via an aesthetic vision that contributes little in upgrading the quality of life for the poor.

This chapter investigates how the policies of RAY have been played out on the ground. Taking the case of RAY's first in-situ redevelopment project at Kathputli Colony in West Delhi, the chapter tries to analyze the drawbacks and opportunities within the scheme with a direct impact on how basic services are provided to and accessed by the marginalized in the city. The observations and recommendations made within this chapter build on the works of Amitabh Kundu (2012), Gautam Bhan (2009), Ananya Roy (2013), and Asher D. Ghertner (2010) that largely focus on slum evictions, housing inequities, and policies on affordable housing and care.

The chapter is divided into three parts: The first part provides an overview of the RAY scheme and its redevelopment proposal at Kathputli Colony; the second part investigates how the community's eviction has affected their access to basic services, employment, and 
communal facilities; the final part outlines the interrelations between the different conceptions of care in the Kathputli project and explores a new alternative approach to slum redevelopment.

\section{The Kathputli Colony and RAY: An Overview}

In terms of population, between 2000 and 2020 Delhi has been the fastest growing city in the world (Satterthwaite 2020) (see Figure 12.1).

This unprecedented growth has been a result of poverty-induced migration from the rural to the urban areas in search of better life and employment opportunities. The skyrocketing prices of land and real estate in the city and the struggle to access the formal housing market have over several years compelled the incoming transient migrants to "occupy marginal lands typified by poor housing stock, congestion and obsolescence" (Gupta and Gupta 2017: 3).

The story of the Kathputli community is similar. In the 1970s a troupe of itinerant performers that once served in the royal courts of the northwestern state of Rajasthan migrated to the capital city and settled in West Delhi's Shadipur region. The group decided to settle on a small plot of land in close proximity to the Shadipur bus depot that made it easier for them to commute and perform across the city. Over the years, as the word about this thriving community in Delhi spread, the colony began to welcome acrobats, singers, dancers, traditional healers, actors, woodcarvers, weavers, craftsmen, and magicians from the farthest corners of the country.

Like any other migrant community in the city, the people of Kathputli became an indispensable part of their immediate community. From helping out as housemaids, nurses, daycare providers, running small businesses, and working as manual labor, the colony and its people were integral for the sustenance of their neighborhood. Yet, the living conditions of this community of almost 3,700 households on a 5.22 hectare plot of land were decrepit and neglected, marked by inadequate water supply, poor sewage, drainage, waste management, and

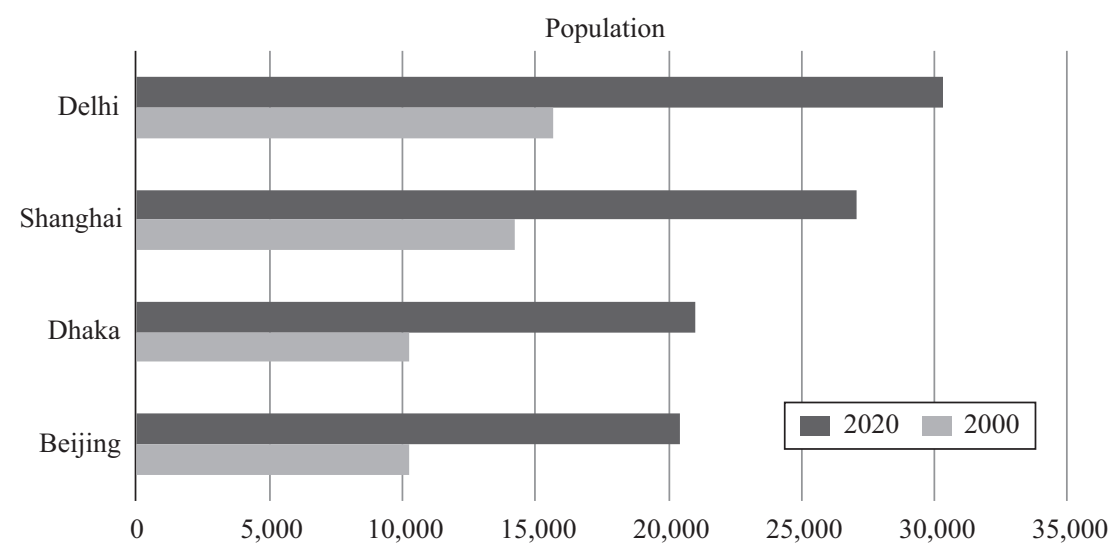

FIGURE 12.1 Top four out of the world's 20 largest cities in 2020 by annual population growth from 2000 to 2020 (in thousands). Data from Satterthwaite (2020). Source: Niroopa Subrahmanyam, 2020. 
the lack of other crucial infrastructure such as community halls, hospitals, schools, and essential commodities (Banda et al. 2013).

With time, owing to the newly constructed subway station, the proximity to the bus depot, and its connectivity to fast-growing neighborhoods like the Naraina industrial area, Shadipur, and Kirti Nagar, this small plot of land became prime real estate (see Figure 12.2).

The deteriorating conditions of the slum and the increasing value of its real estate prompted the state to push for the slum's redevelopment. The first proposal was made in 1986. The colony was to be displaced to a small plot of land in the outskirts of South Delhi. In 1996 a similar proposal followed, this time with a proposal to displace the colony to another part of southwest Delhi. After much resistance by the community, both proposals were rejected on the grounds that the resettlement housing that was offered was on the outskirts of the city where transport infrastructure was poor and access to services and employment limited.

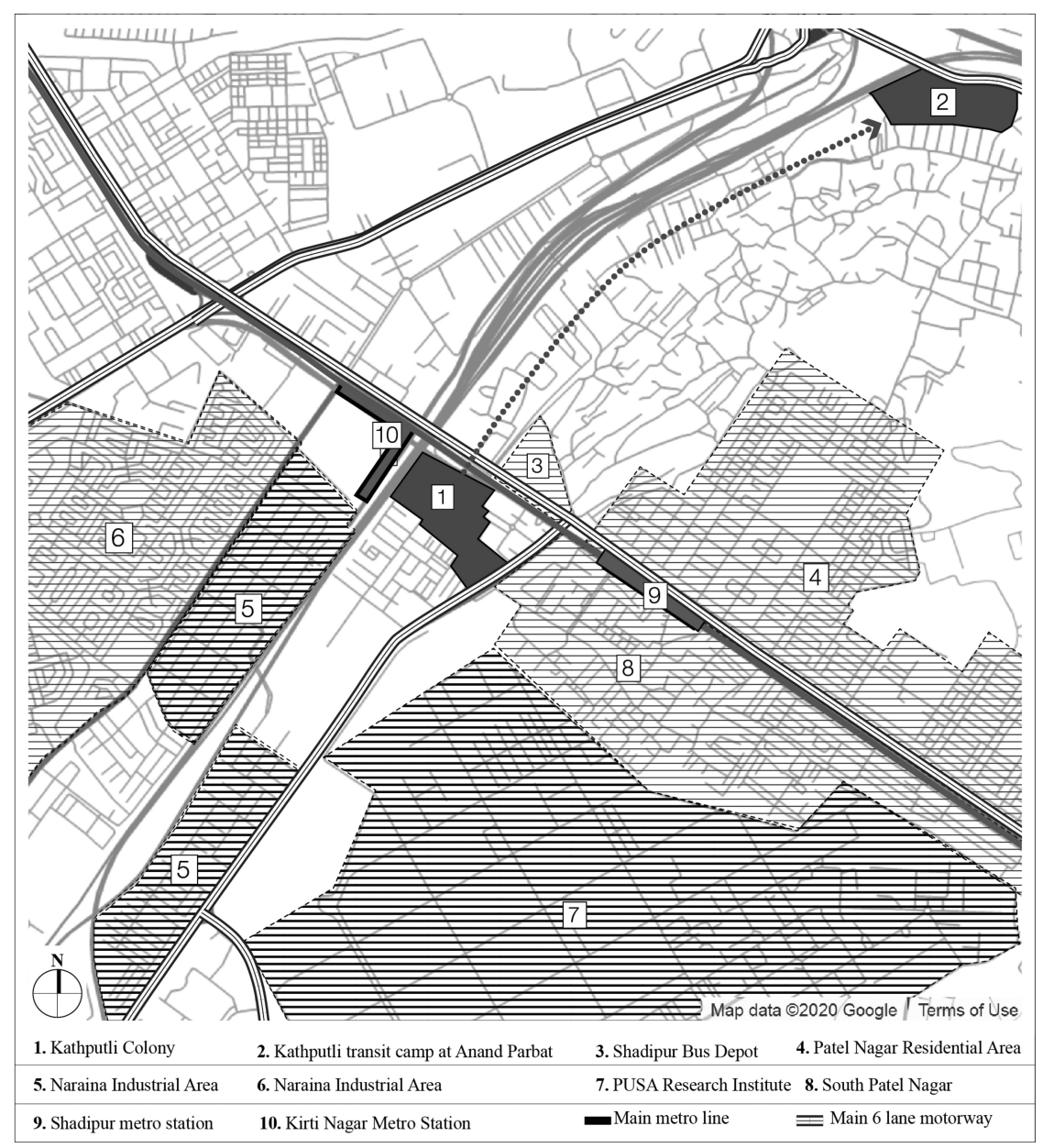

FIGURE 12.2 Map showing Kathputli Colony. Centrally located between multiple transport points along the main road. The Kathputli transit camp, Anand Parbat, can be seen to the north a little over two kilometers away. Source: Niroopa Subrahmanyam, 2020. 
While the people of Kathputli were able to collectively resist their permanent relocation, the fate of many slum communities across the capital city was not as favorable. The state housing authority, Delhi Development Authority (DDA), had by this time already carried out a series of eviction drives to rehabilitate vulnerable communities into new social housing scattered across the periphery of the city. However, the growing discontent and resistance displayed by the Kathputli community as well as the activists and NGOs supporting the community compelled the state to rethink its policies of rehabilitation.

This led to the initiation of the RAY in 2007—a new affordable housing scheme issued by the DDA that adopts the Slum Free City Plan of Action (SFCPoa) standards set within the Delhi Master Plan 2021. The main objectives of the scheme include:

- Enabling all slums to avail basic services regardless of whether they are notified or non-notified ${ }^{3}$

- Planning for affordable housing stock for the poor; and

- Initiating crucial policy changes required to facilitate the same.

The scheme exclusively prohibits the relocation of slum households and instead looks at an in-situ model within which the slum residents will be provided housing, sanitation, and water on the land they occupy. Additionally, it mandates the provision of social amenities such as pre-schools, childcare centers, health centers/sub-centers, livelihood centers, etc.

In 2009, out of 21 projects the DDA identified within the Delhi SFCPoa, it decided to award its first in-situ project to the Raheja developers. The developers were to initiate the redevelopment of the 5.22 hectares of land occupied by the Kathputli Colony. Under the PPP model, Raheja's were obligated to reserve $60 \%$ of the plot area for the Kathputli redevelopment while $40 \%$ could be used by the developer as commercial or non-subsidized housing. Within this $60 \%$ plot area the developer must also accommodate the social amenities described earlier including underground water tanks, domestic water supply, and horticultural works. Additionally, the developer is obligated to lay all the internal roads, pay the appropriate authorities for the installation of an electric substation, and obtain necessary building clearances from all the concerned state authorities. The guidelines estimated that the construction of the new housing could take up to two years during which time the Kathputli residents would be relocated to a transitional camp that would be built by the developer.

At first glance, a formalized scheme for the temporary relocation of the community and the promise of a new home on the land they occupy may seem productive, cost effective, and most importantly less risky for the people of Kathputli. However, a few key factors added to the community's reluctance to relocate: notably the confusion around their eligibility to a house in the transit camp; the uncertainty of stable employment or means of livelihood near the transit camp; the fear of being uprooted from their community; and finally the added expense of commuting to schools, work, and places of worship. The community therefore expressed their grievances to concerned neighborhood authorities and with the help of their representatives, NGOs, and activists petitioned and appealed to the state to provide more clarity and assurances regarding the procurement of a new home. Very soon, contrary to the objectives of RAY, the state began to reveal the requirements for eligibility under which it mandated the Kathputli residents to present valid proof of residence, issued no later than a cutoff date that, following several extensions, was confirmed as June 4, 2009. 
Soon enough, many households that were in possession of a valid proof of residence decided to take the necessary steps toward the improvement of their living conditions and started relocating to the newly built transit camp two kilometers away from the Kathputli site (see Figure 12.2). For the households that could not prove their eligibility there was an imminent risk of slipping into homelessness. In the period between 2014 and 2016 some 500 households decided to make the reluctant transition to the transit camp. In 2016, after increasing pressure from activists and the remaining residents of Kathputli, it was agreed that more time be given to households left behind to make their own decision regarding relocating to the transit camps. In October 2017, with the help of the police and paramilitary forces, the DDA finally decided to begin the process of demolishing the Kathputli colony despite the continued occupancy of the site. This illegal demolition of the colony, the first of many, flattened 400 homes and immediately pushed several households within the community into homelessness. Until the end of 2017, some 500 households continued to occupy whatever little is left of the site (Walczak 2017).

\section{Slum Redevelopment and the Conflicting Values of Care}

One of the key oversights of the state was its inability to anticipate the number of households that needed to be rehabilitated as part of the Kathputli project. This unpreparedness favored their decision to differ from the original objectives of RAY and set clear criteria of eligibility for the Kathputli community to procure regularized housing. These criteria left the community with only two alternatives - either to meet the requirements of eligibility and gain access to an upgraded quality of life or to become homeless. Even so, despite proving their eligibility, the confusion over the documents that could suffice as residence proof, the lack of transparency in the process of its evaluation, and the shifting cutoff dates further made the process of relocation intimidating and arduous for the Kathputli community.

While the physical attributes of the colony's built environment are comparable to slum settlements across the city, the diverse composition of the community is unique and presents new opportunities for making RAY more inclusive, participative, and adaptable. Yet, on ground the practices and policies of RAY regarding the eviction of the slum dwellers and the protection of their rights have revealed the contrary. For the community the process of eviction not only became a cause of fear and confusion it also played a central role in the shifting and oftentimes contradicting values of care between the household, the community, and the state, which determined the sentiment toward their own rehabilitation process.

Presently RAY's in-situ redevelopment model proposes the upgrade of slums through the construction of newly built homes. In the case of Kathputli, 2,800 households will be accommodated within a series of interconnected 14-story high-rise towers. It is expected that the provision of these newly built homes will be critical in addressing two major concerns central to the state's slum preventive strategy incorporated in the Delhi SFCPoa. First is the question of the spatial illegality of the slum and second the need for capital accumulation. The state believes that social housing will help the Kathputli community in providing access to a secure tenure, organizing itself within the 'formal' city and by that effect allowing them easy access to basic services. The relocation of the slum community to transit camps is therefore a crucial first step of this overall domino effect.

However, the policies shaping this process of redevelopment and relocation have raised a range of concerns many of which are also outlined within the formal legal brief submitted 
by the community in 2014 (Bhule Bisre Kalakar Co-Operative Industrial Production Society Ltd. and ORS Petitioners v Union of India and ORS Respondents 2014).

The incomplete enumeration on part of the DDA accounted for only 2,800 out of the roughly 3,700 families as eligible for a replacement unit in the new apartment towers. This was aggravated further by the lack of transparency on part of DDA to reveal the official list of beneficiaries after repeated requests by the community and their representatives and lack of any provisions to rehabilitate the 'omitted' families. Further, the proposal for a high-rise tower did not take into consideration the specific design elements that would be critical to support the traditional lifestyle of the community. The lack of space for circulation, training, informal performances, workshops, storage, etc. made the community question the value of such a project in uplifting their standard of life. Lastly, the policies within RAY specify that the replacement unit only be transferred legally to an eligible slum household on a yearly rent if they agree not to transfer or lease out the property for another ten years. While such a proposition is a good preventive measure to stop the creation of slums and limit the misuse of the rental contract, it also prevents a community such as Kathputli that work largely within the informal sector from relocating to other parts of the city in search for better employment opportunities.

Thus, although redevelopment may provide a less complicated means of providing tenurial security to the poor yet, as seen in Kathputli, such a proposal creates indeterminate criteria for eligibility and provides no alternatives in the case they are not fulfilled. It forces the community into high-rise towers where they will be unable to combine their work-life traditions and also binds them into strict, inflexible ten-year contracts as a preventive measure, making the scheme counteractive to their personal and professional aspirations.

Another matter of contention in this case is the fact that the community is largely stratified along lines of geographical origin (Banda et al.2013). It is composed of eight sub-groups each with their own community representative. On the ground these lines also reflect economic disparities - the older communities that have lived longer in the colony had larger, well-equipped homes at the center of the site while the relatively new residents lived in more tenuous structures with limited access to the community or the community services. This has played a central role in influencing the community's attitudes toward the relocation and the redevelopment process. While the relatively new households were more open to relocating to transit camps, the older households were not convinced by the necessity for redevelopment. Added to this was a generational gap that was visible in the differing sentiments between the young and the old. While the young believed that the temporary relocation was a small price to pay for upgrading their quality of life, the older generation saw this as a threat to their artistic traditions.

However, overall, all parties had a general consensus on the importance of sustaining the identity and culture of the community. For this reason, they saw the proposal for relocating to two separate transit camps, the lack of stable employment opportunities in the vicinity of the camps, and the eventual transition to isolated, non-incremental high-rise towers as an imminent threat to the order and traditions of the community.

Further, the demolition of the colony also led to the dismantling of the social fabric that the community had so meticulously developed over several decades. This complex urban fabric included the informal infrastructures for community and commercial facilities, temporary schools, places of worship, crèches, and small clinics. Not only did the close proximity of these services fulfill the mobility and accessibility needs of the community, it also 
contributed toward the community's overall social, mental, and physical well-being. The visible lack of proper policies and action plans within RAY to map, survey, and analyze these pre-existing services that are a common feature of slums around the city displays its disregard toward the flexible and incremental nature of services that are crucial for the sustenance of every slum community. The demolition of Kathputli therefore is a missed opportunity of investing and upgrading in a care ecosystem that is already affordable and accessible to the community.

\section{Toward Slum Upgrading}

The Kathputli project presents two contradictions to the main objective of RAY to make basic services universally accessible to the urban poor (see MoHUPA 2013). The provisions of RAY are exclusive and have only been extended to the Kathputli community through unclear but strict criteria for eligibility, which sidelines almost 700 households from the rehabilitation project. With an average family size of four, almost 3,000 people have been denied the provision of a house and access to basic services purely on the basis of their ineligibility to qualify for the scheme. Furthermore, in cases where the households are eligible slum dwellers will have to overcome complex socio-cultural challenges such as disruption of work-life balance, dismantling of the community's social hierarchy, and compromising the spatial rituals of their artistic traditions to be able to resume life in cramped high-rise towers and assimilate into the formal system.

Evidently, the vision of basic services for all embedded within RAY is not accessible to all households within the Kathputli colony let alone the larger population of urban poor living in the capital city. The households that can access the scheme are forced to abate their own scope and ability for self-provision and instead depend on state-provided care. While this dependence on state systems is healthy and much needed yet, for the itinerant populations of the urban poor living in the city and largely dependent on informal jobs and unsteady incomes, a better quality of life and access to basic services will require larger systemic changes to their incomes and employment opportunities as well. Thus, while redevelopment may seem necessary for an immediate upgrade in the quality of life of the urban poor, in the long run, however, continued access to basic services must be ensured via strategic incremental and affordable solutions.

For RAY, the first step in this direction would require moving away from guaranteeing basic services via in-situ redevelopment of the slums that, as observed in the case of Kathputli, comes at a huge mental, social, and financial cost and in lieu of focusing on 'in-situ upgrading' of slums in order to overcome and/or make use of the existing physical and social vulnerabilities and opportunities presented in them. Of course, this does not imply that the conditions within the slum by itself are ideal for creating the provisions for care, yet, one must acknowledge that slum clusters tend to develop in the cracks of the ordered city, already in close proximity to employment sources, schools, health-care services, etc. (Chatterji 2019). Thus, by their very nature they are already opportunistic, affordable, and incremental. In-situ upgrading would therefore capitalize on these existing livelihood linkages and focus on the incremental upgrading of the individual households and community services already present in and around the existing slum settlement.

Such a scheme presents a few benefits. Since RAY is already chronically financially dependent on private investments, making in-situ upgrading a priority intervention will make 
delivering basic services a very feasible proposition for the state to invest in and the urban poor to self-finance. Moreover, the additional expenses that the community was bearing in order to access better equipped health/education/community facilities away from their neighborhoods can now be redirected toward making incremental improvements to their own households at a pace that corresponds to their irregular resource flows. Over time, these small increments can give sizable dividends in the form of well-maintained and accessible health-care facilities, improved hygiene, and better living spaces and increased sense of community.

This ability of a slum to improve their own livelihoods will help increase their legitimacy as a self-sufficient community and inadvertently give them effective protection against any future demolition or eviction (Bhan et al. 2014). This effective protection can take slum upgrading a step further by buying the community more "development time," which is a formal no-eviction guarantee for settlements facing eviction that may or may not eventually result in ownership (ibid.: 20). This guarantee may be awarded to slum communities in exchange for a low rent or no rent over a stipulated period of time, usually long enough to see substantive gains in their quality of life. During this time individual households within the community can have access to additional loans on top of their own investments to facilitate low-cost interventions to improve the standard and stability of their houses or collective loans to invest toward the maintenance of community services. These loans can be recovered as a surcharge on their rents and will impose no additional financial burden to slum households.

It is expected that once the stipulated time period is over each household within the community is able to display a better quality of life and access well-maintained and functional community services and is therefore either willing to bear more risk and transition to legal rental/ownership contracts for their own house or will have enough financial savings and economic resources to be able to directly access a new house and better services via the formal housing market. Of course, it is evident that such a proposition is only a transitional measure and would require at some level more comprehensive systematic changes. Yet, it can be argued that in the short and the long term, upgrading through a no-eviction guarantee is a more secure and affordable option than the RAY scheme and ensures a continued access to regularized care for the poor.

To summarize, in-situ upgrading can be seen as a counter concept to the current narrative for in-situ redevelopment. By giving the poor a chance to upgrade unscrupulous urbanization, private participation can be limited and the state can become more accountable toward financing the basic services in and around the vicinity of slums. It also empowers the urban poor by encouraging them to afford, maintain, and incrementally improve their houses and community services at their own pace and income levels. Additionally, including provisions for the poor to prematurely transfer or terminate housing rental contracts will benefit the poor by buffering the financial as well as time-bound implications of re-entering the formal housing market at their own convenience.

Rethinking the role of the urban poor as stakeholders rather than beneficiaries in the process of upgrading their quality of life will be fundamental in addressing the emerging struggles for accessing urban care in future cities. Upgrading rather than redeveloping slums will not only ease the access to housing and basic services for the existing and expected itinerant populations coming to the city but will also contribute significantly toward the making of an equitable Delhi. 


\section{Notes}

1 Regularized housing refers to any housing built on land designated for residential land use purposes.

2 Unplanned settlements, in the case of Delhi, are very diverse, with varying conditions of tenure, ownership, and infrastructure facilities. Presently, Delhi has eight types of settlements out of which seven are unplanned types: JJ Clusters, Slum Designated Areas (SDA), Unauthorized Colonies, JJ Resettlement Colonies, Regularized Unauthorized Colonies, Rural Villages, and Urban Villages. The Kathputli Colony falls within the JJ Clusters category (CPR 2015).

3 Each Indian state uses different policies to determine whether or not a slum can obtain a legal status. These criteria are loosely based on the guidelines and definitions enclosed within the Slum Improvement and Clearance Act of 1956 and the legal status serves as a prerequisite for the slum to receive municipal services. De facto slums that secure de jure status are called notified slums while the ones that do not are called non-notified slums.

\section{References}

Bhan, G. (2009) "This Is No Longer the City I Once Knew": Evictions, the Urban Poor and the Right to the City in Millennial Delhi. Environment and Urbanization 21(1): 127-142.

Bhan, G., Anand, G., Harish, S. and Shetty, P. (2014) Policy Approaches to Affordable Housing in Urban India: Problems and Possibilities [Online]. Bangalore: Indian Institute for Human Settlements. Available at https://www.academia.edu/38136941/Policy_approaches_to_affordable_housing_in_urban_India _Problems_and_Possibilities [Accessed 3 May 2020].

Bhule Bisre Kalakar Co-Operative Industrial Production Society Ltd. and ORS Petitioners v Union of India and ORS Respondents (2014) W.P.(C) 1290/2014 and CM Appl. 3834/2014.

Banda, S., Vaidya, Y. and Adler, D. (2013) The Case of Kathputli Colony: Mapping Delhi’s First In-Situ Rehabilitation Project. CPR Working Paper 3 [Online]. New Delhi: Centre for Policy Research. Available at https://www.cprindia.org/research/papers/case-kathputli-colony-mapping-delhis-first -situ-slum-rehabilitation-project [Accessed 12 July 2019].

Centre for Policy Research (CPR) (2015) Categorization of Settlement in Delhi [Online]. Available at http: //citiesofdelhi.cprindia.org/wp-content/uploads/2015/09/Categorisation-of-Settlement-in-Delhi .pdf [Accessed 2 May 2019].

Chatterji, S. (2019) Re-Housing Slums as if People Matter. In V. Bharne and S. Khandekar (eds.) Affordable Housing, Inclusive Cities. New York: Oro Editions, pp. 157-161.

Ghertner, D.A. (2010) Calculating Without Numbers: Aesthetic Governmentality in Delhi's Slums. Economy and Society 39(2): 185-217.

Gupta, M. and Gupta, R. (2017) Demand for Rental Housing: Evidence from Slum Settlements in Delhi. Urbanisation 2(1): 9-27.

Kundu, A. (2012) Report of The Technical Group on Urban Housing Shortage (TG-12) (2012-2017) [Online]. New Delhi: Ministry of Housing and Urban Poverty Alleviation. Available at https://sm artnet.niua.org/sites/default/files/resources/urban-housing-shortage.pdf [Accessed 12 May 2020].

Ministry of Housing and Urban Poverty Alleviation (MoHUPA) (2013) Rajiv Awas Yojana: Scheme Guidelines 2013-2022 [Online]. Available at https://smartnet.niua.org/sites/default/files/resources/ RAYGuidelines.pdf [Accessed 7 June 2019].

Roy, A. (2013) Slum-Free Cities of the Asian Century: Postcolonial Government and the Project of Inclusive Growth. Singapore Journal of Tropical Geography 35(1): 136-150.

Satterthwaite, D. (2020, 24 March) The World's Fastest Growing Cities. International Institute of Environment and Development [Online]. Available at https://www.iied.org/worlds-fastest-growing -cities [Accessed 28 September 2020].

The Slum Areas (Improvement and Clearance) Act 1956 [Online]. New Delhi: Government of India. Available at http://legislative.gov.in/actsofparliamentfromtheyear/slum-areas-improvement-and -clearance-act-1956 [Accessed 14 October 2020].

Walczak, G. (2017) No Strings Attached: Reimagining the Redevelopment of Delhi's Kathputli Colony. Master Thesis, Carleton University. 